\title{
Abnormal hypermethylation of promoter region downregulates chemokine CXC ligand 14 expression in gastric cancer
}

\author{
CHANGYUAN HU ${ }^{1 *}$, FENG LIN $^{2 *}$, GUANGBAO ZHU $^{1}$, XIANGYANG XUE $^{3}$, \\ YUJIE DING ${ }^{1}$, ZHIGUANG ZHAO ${ }^{4}$, LIFANG ZHANG ${ }^{3}$ and XIAN SHEN ${ }^{1}$ \\ ${ }^{1}$ Department of General Surgery, The First Affiliated Hospital of Wenzhou Medical University, Ouhai District, \\ Wenzhou, Zhejiang 325035; ${ }^{2}$ Department of General Surgery, Taizhou First People's Hospital, Taizhou, Zhejiang 318020; \\ ${ }^{3}$ Department of Microbiology and Immunology, Institute of Molecular Virology and Immunology, Wenzhou \\ Medical University, Ouhai District, Wenzhou, Zhejiang 325035; ${ }^{4}$ Department of Pathology, The Second Affiliated \\ Hospital of Wenzhou Medical University, Lucheng District, Wenzhou, Zhejiang 325000, P.R. China
}

Received June 13, 2013; Accepted July 22, 2013

DOI: 10.3892/ijo.2013.2078

\begin{abstract}
CXCL14, a new member of the CXC subfamily of chemokines, is differentially expressed in several types of tumors. The expression of CXCL14 and its clinical significance in gastric cancer are unclear to date. In this study, the expression of CXCL14 was detected by quantitative PCR and immunohistochemistry assay. DNA methylation was analyzed by bisulfite sequencing PCR. Student's t-test and Kruskal-Wallis $\mathrm{H}$ test were used to evaluate the differences of the CXCL14 expression between the groups. Kaplan-Meier survival curve and Cox regression model were used to evaluate the clinical significance of CXCL14 expression in gastric cancer. Data indicated that the levels of CXCL14 mRNA declined $(\mathrm{P}<0.001)$ in gastric carcinoma tissues compared to the paired normal tissues. Immunohistochemical analysis also showed the decrease of CXCL14 protein in the tumor tissue $(\mathrm{P}<0.001)$. Analysis of $\mathrm{CpG}$ islands methylation in CXCL14 promoter region and first exon area indicated that the abnormal hypermethylation of promoter region in tumor tissue is one of the mechanisms causing the reduction. When gastric cancer cells were demethylated with 5-Aza-2'-deoxycytidine, CXCL14 expression was restored. Downregulation of CXCL14 was associated with the depth of penetration $(\mathrm{P}<0.001)$ and posi-
\end{abstract}

Correspondence to: Dr Xiangyang Xue, Department of Microbiology and Immunology, Wenzhou Medical University, Ouhai District, Wenzhou, Zhejiang 325035, P.R. China

E-mail:wzxxy@aliyun.com

Dr Xian Shen, Department of General Surgery, The First Affiliated Hospital of Wenzhou Medical University, Ouhai District, Wenzhou, Zhejiang 325035, P.R. China

E-mail: shenxian5166@gmail.com

${ }^{*}$ Contributed equally

Key words: BRAK/CXCL14, gastric cancer, DNA methylation, survival analysis tively correlated with prognosis in stage III/IV $(\mathrm{P}=0.046)$. In conclusion, it is possible that CXCL14 is involved in the development and progression of gastric cancer. Hypermethylation in the promoter is one of the reasons that CXCL14 has lower expression in gastric adenocarcinoma tissues. The level of CXCL14 expression may be a valuable adjuvant parameter in predicting the prognosis of gastric cancer patients and, thus, a potential therapeutic target.

\section{Introduction}

According to 2013 the National Comprehensive Cancer Network (NCCN) Guidelines, gastric adenocarcinoma is spreading globally, especially in Asian countries, such as Japan and China. Gastric carcinoma is the fourth most common malignancy and the second leading cause of death worldwide, with estimated 900,000 new cases per year and a 20\% 5-year survival rate $(1,2)$. The oncogenesis and development of gastric cancer is still vague. The surrounding tumor microenvironment has begun to be recognized as an active participant in the development and progression of cancer. Chemokines, secreted by cells in the tumor microenvironment, can regulate fundamental biological processes in both tumor and stromal cells, including anti-angiogenesis, activation of host specific immunity and autocrine stimulation of cell growth (3-5). It has been reported that there is a difference of chemokine receptors and function between tumor cells and normal cells $(4,5)$, which gives rise to the hypothesis that dysregulation of chemokines may take part in the development of the malignancy.

CXCL14 (also named BRAK), one of the CXC chemokines, was first reported by Hromas et al (6). Its gene locates in $5 \mathrm{p} 31.1$ chromosome and is constituted by 77 amino acids (7). Physiologically, CXCL14 tends to play a homeostatic role which was constitutively expressed in cerebrum, small intestine, kidney, and epithelium, but not in lymphoid tissue (8-10). In common inflammation, CXCL14 was inclined to decrease $(11,12)$. However, the opposite result of increased CXCL14 was seen in infiltrating inflammatory cells around tumor $(9,13)$. As a member of ELR (Glu-Leu-Arg motif immediately prior) 
negative chemokine family, CXCL14 contains multiple functions of anti-angiogenesis, chemotaxis to natural killer cells, B-cells, macrophages, monocytes, and immature dendritic cells $(3,8,11,14,15)$.

Beginning with breast cancer, several studies showed its low or absence of expression of CXCL14 in renal carcinoma, lung cancer, head and neck squamous cell carcinoma, and cervical cancer $(6,8,16,17)$. However, CXCL14 has been found at high levels in part of prostate and pancreas cancer $(18,19)$. The expression of CXCL14 and its clinical significance in gastric cancer is poorly understood. In the present study, we explored the expression and clinical significance of CXCL14 in gastric cancer tissues. Further investigation showed downregulation of CXCL14 in gastric cancer tissues was caused by unusual methylation in its promoter region. Our findings suggest that the anticancer function of CXCL14 provides a new approach in gastric cancer diagnosis and treatment.

\section{Materials and methods}

Patients and specimens. All the gastric adenocarcinoma patients in the study cohort, diagnosed by endoscopic biopsy, were admitted for surgical treatment in the First Affiliated Hospital of Wenzhou Medical University (Zhejiang Province, China) from December 2008 to April 2009. None received radiation therapy or chemotherapy before operation and received strict chemotherapy after surgery according to the NCCN gastric cancer guidelines. The histopathological diagnosis of gastric adenocarcinoma was confirmed by the Pathology Department according to the criteria of the World Health Organization after the operation. The patient characteristics and clinicopathological features are listed in Table I. Paired specimens of gastric adenocarcinoma tissues and corresponding normal gastric tissues (obtained from negative resection margin) were obtained from the above patients. Each sample was divided into several fractions. Some were snapfrozen in liquid nitrogen within $30 \mathrm{~min}$ of the resection and stored for RNA/DNA extraction. The remaining part of the sample was formalin-fixed and paraffin-embedded for immunohistochemistry. Informed written consent was obtained from each patient and the study was approved by the Human Research Ethics Committee at the First Affiliated Hospital of Wenzhou Medical University.

Tumor cell lines and treatment. Gastric cancer cell lines, AGS obtained from the American Type Culture Collection (ATCC ${ }^{\circledR}$, Manassas, VA, USA), SGC7901, BGC823 and MGC803 were purchased from the Type Culture Collection of Chinese Academy of Sciences (Shanghai Institute of Biochemistry and Cell Biology ${ }^{\circledR}$, Chinese Academy of Sciences, Shanghai, China), cultured in Ham's F-12K medium (Gibco Life Technologies ${ }^{\circledR}$, Shanghai, China) supplemented with $10 \%$ fetal bovine serum at $37^{\circ} \mathrm{C}$ under $5 \% \mathrm{CO}_{2}$. Cells, harvest from $25 \mathrm{~cm}^{2}$ culture flasks, were seeded in 6-well plate with low density $\left(1 \times 10^{6}\right.$ cells per well). Twenty-four hour adhesion and $16 \mathrm{~h}$ serum starvation was performed before drug treatment. The cells were treated by 5-Aza-2'-deoxycytidine (Sigma ${ }^{\circledR}, \mathrm{St}$. Louis, MO, USA) for 5 days with fresh medium containing the drug changed every $24 \mathrm{~h}$. The final concentration of drug in the well was $0,5,10,15,25 \mu \mathrm{mol} / 1$, respectively. CXCL14
mRNA, DNA and protein were respectively isolated for further research.

RNA isolation and purification. Total RNA were extracted from gastric adenocarcinoma tissues, corresponding normal gastric tissues and cancer cell lines using TRIzol reagent (Invitrogen Life Technologies ${ }^{\circledR}$, Grand Island, NY, USA) following the supplier's instructions with some modifications. Briefly, the extracted RNA precipitated in isopropanol were incubated at $-20^{\circ} \mathrm{C}$ overnight to enhance precipitation efficiency of low-molecular-weight RNA. Quantified by the ultraviolet spectrophotometer (Beckman Coulter $^{\circledR}$, Miami, FL, USA), RNA was purified with DNase I (Thermo Scientific ${ }^{\circledR}$, Waltham, MA, USA) and re-extracted using phenol/chloroform according to the manufacturer's instructions. The pure RNAs were dissolved in diethylpyrocarbonate (DEPC)-treated water and stored at $-80^{\circ} \mathrm{C}$. The concentration and purity of total RNA were qualified by the ultraviolet spectrophotometer at 260 and $280 \mathrm{~nm}$. Only the RNA samples with ratio of $>2.0$ A260/A280>1.8 were used for the experiment.

Reverse transcription PCR and real-time PCR. First-strand complementary DNA was reverse transcribed with ReverTra Ace $^{\circledR}$ qPCR RT kit (Toyobo ${ }^{\circledR}$, Tokyo, Japan) from $1 \mu \mathrm{g}$ of total RNA and preserved at $-20^{\circ} \mathrm{C}$ until use. We extended the reverse transcription time to $60 \mathrm{~min}$ in comparison with specification. CXCL14 RNA expression was assessed by real-time PCR with RNA-direct ${ }^{\mathrm{TM}}$ SYBR $^{\circledR}$ Green Real-time PCR Master Mix (Toyobo) and specific primers (forward, 5'-AGCCAAAGTACC CGCACTG-3'; and reverse, 5'-AGACCCTGCGCTTCTCG TTC-3'; 156 bp). hGAPDH was chosen as internal control gene (forward, 5'-CAGGGCTGCTTTTAACTCTGGTAA-3'; and reverse, 5'-GGGTGGAATCATATTGGAACATGT-3'; 101 bp). In StepOne ${ }^{\mathrm{TM}}$ Real-Time PCR system (Applied Biosystems ${ }^{\circledR}$, Grand Island, NY, USA), PCR cycles involved at $95^{\circ} \mathrm{C}$ for $5 \mathrm{~min}$; then followed by 40 amplification cycles of $94^{\circ} \mathrm{C}$ for $30 \mathrm{sec}, 57^{\circ} \mathrm{C}$ for $30 \mathrm{sec}, 72^{\circ} \mathrm{C}$ for $30 \mathrm{sec}$. Melting curves were generated for each real-time PCR to verify the specificity of each PCR reaction. Duplication was performed in real-time PCR for accuracy judgement.

Western blot analysis. Protein, obtained from samples by cell lysis buffer (Beyotime ${ }^{\circledR}$, Shanghai, China) was quantified to $50 \mu \mathrm{g}$ per lane by Enhanced BCA Protein Assay kit (Beyotime). After separating in 12\% PAGE gels and transferring to nitrocellulose membrane, the membrane was blocked with $5 \%$ defatted milk in tris-buffered-saline with Tween (TBS-T) for $2 \mathrm{~h}$. The same protein lysates were incubated with CXCL14 antibody $\left(12 \mathrm{kDa}, 0.2 \mu \mathrm{g} / \mathrm{ml}, \mathrm{Abcam}^{\circledR}\right.$, Cambridge, MA, USA) and $\beta$-actin antibody (42 kDa, dilution 1:1,000, Beyotime) at $4^{\circ} \mathrm{C}$ overnight, respectively. Followed by washing, the related horseradish-peroxidase (HRP) conjugated secondary antibodies (Beyotime) were incubated for $1 \mathrm{~h}$ at room temperature $\left(25^{\circ} \mathrm{C}\right)$. BeyoECL Plus (Beyotime) was used for detection of the final chemiluminescence reaction.

Immunohistochemistry. Paired formalin-fixed and paraffinembedded tissue blocks $(n=60)$ from gastric adenocarcinoma and normal resection margin were cut into $5 \mu \mathrm{m}$ sections 
Table I. Clinicopathological features and CXCL14 mRNA $\left(2^{-\Delta \Delta C t}\right)$ of 60 patients.

$\begin{aligned} & \text { Clinicopathologic } \\ & \text { variables }\end{aligned}$
n

\section{Gender}

\section{Male}

Female

46

$140.474(0.010-1.475)$

Age (years)

$<60$
$\geq 60$

Tumor location

Upper third

Middle third

Lower third

$\begin{array}{lll}22 & 0.592(0.170-1.226) & 0.745 \\ 38 & 0.556(0.010-1.475) & \end{array}$

Tumor size $(\mathrm{cm})$

$$
\begin{aligned}
& <5 \\
& \geq 5
\end{aligned}
$$$$
37 \quad 0.600(0.025-1.475)
$$

$23 \quad 0.528(0.010-1.349)$

\section{Differentiation}

Well or moderately
Poorly or none

$110.770(0.170-1.349)$

$49 \quad 0.473(0.010-1.475)$

Primary tumor ${ }^{\mathrm{a}}$

T1
T2
T3
T4

$$
\begin{array}{rr}
6 & 0.439(0.325-0.581) \\
6 & 0.255(0.072-0.523) \\
25 & 0.390(0.010-1.097) \\
23 & 0.879(0.025-1.475)
\end{array}
$$

$<0.001^{b}$

Regional lymph nodes ${ }^{\mathrm{a}}$

N0
N1
N3

$\begin{array}{rll}8 & 0.551(0.072-1.226) & 0.121 \\ 7 & 0.247(0.085-0.541) & \\ 29 & 0.583(0.025-1.349) & \\ 16 & 0.694(0.010-1.475) & \end{array}$

Anatomic stage

Stage I

Stage II

Stage III

Stage IV

$$
\begin{array}{rl}
6 & 0.334(0.072-0.581) \\
8 & 0.576(0.170-1.226) \\
31 & 0.678(0.010-1.349) \\
15 & 0.475(0.085-1.475)
\end{array}
$$

Carcinoembryonic antigen (CEA; $\mu \mathrm{g} / \mathrm{l})$

$$
\begin{aligned}
& \leq 5 \\
& >5
\end{aligned}
$$$$
49 \quad 0.575(0.025-1.475)
$$

$$
110.540(0.010-1.226)
$$

Carbohydrate antigen 19-9

(CA19-9; U/ml)

$\begin{array}{llll}\leq 37 & 43 & 0.522(0.072-1.350) & 0.640^{\mathrm{b}} \\ >37 & 17 & 0.688(0.010-1.475) & \end{array}$

${ }^{a}$ According to NCCN Guideline Version 2.2013 Gastric Cancer Staging. ${ }^{\mathrm{b}}$ Calculated with Kruskal-Wallis $\mathrm{H}$ test. and adhered to $0.1 \%$ poly-L-Lysine treated glass slides (Maixin-Bio ${ }^{\circledR}$, Fuzhou, Fujian Province, China); dewaxed in oven at $61^{\circ} \mathrm{C} 1 \mathrm{~h}$ and a series of xylene; rehydrated using graded ethanol (100, 90, 80 and 70\%); followed by distilled water. Antigen retrieval was carried out by high-pressure antigen retrieval for $2 \mathrm{~min}$ in citrate antigen retrieval solution ( $\mathrm{pH} \mathrm{6.0,}$ Maixin-Bio). After cooling to room temperature, slides were washed three times by $0.01 \mathrm{~mol} / 1$ phosphate buffer solution (PBS, pH 7.4). 0.3\% hydrogen peroxide was used to block endogenous peroxidase activity for $10 \mathrm{~min}$ and the primary antibodies $(5 \mu \mathrm{g} / \mathrm{ml}$, Abcam) were incubated in room temperature for $3 \mathrm{~h}$ and 30-min incubation with HRP-conjugated secondary goat anti-rabbit antibodies (Maixin-Bio). The color reaction was developed using the DAB kit (Zhongshan Golden Bridge $\mathrm{Bio}^{\circledR}$, Beijing, China) for $5 \mathrm{~min}$ according to the manufacturer's protocol. Specimens were counterstained with hematoxylin, rinsed in PBS, dehydrated through graded ethanol (80,90 and 100\%) and by dimethylbenzene.

For a semiquantitative analysis of CXCL14 protein expression: -, was graded for no expression; + , was graded for $<25 \%$ expression; ++, was graded for $25-50 \%$; +++, was graded for $>50-75 \%$; and ++++ , was graded for $>75 \%$ expression.

Bisulfite modification and BSP. We obtained the genomic DNAs from paired specimens of tumor/normal gastric tissues and gastric cancer cell lines before/after 5-Aza-2'-deoxycytidine treatment using TIANamp Genomic DNA kit (Tiangen Biotech ${ }^{\circledR}$, Beijing, China) according to their protocol. Before modification with bisulfite, quantified DNA was measured by ultraviolet spectrophotometer. Extracted DNA $(0.5 \mu \mathrm{g})$ from tissues and cells was used for bisulfite modification with EZ DNA Methylation-Gold kit (Zymo Research ${ }^{\circledR}$, Irvine, CA, USA) according to the manufacturer's protocol. Modified DNA was amplified immediately because of the unstable situation of CT conversion. The bisulfite-sequencing PCR primers (16) (forward, 5'-GTTGTGGTATGGGTGTGTAAG-3'; and reverse, 5'-CRCCAAAAACCTCATACTAACC-3') and Taq Hot Start ${ }^{\mathrm{TM}}$ (Takara ${ }^{\circledR}$, Otsu, Shiga, Japan) were necessary for amplifying $\mathrm{CpG}$ islands in the promoter region with the expected product of $505 \mathrm{bp}$ in length. For follow-on research, the PCR reaction solution in T100 thermal cycler (Bio-Rad ${ }^{\circledR}$, Hercules, CA, USA) was geometrically amplified to $50 \mu \mathrm{l}$. After initial denaturation step at $95^{\circ} \mathrm{C}$ for $5 \mathrm{~min}$, the PCR profile was limited to 35 cycles for mutation at $94^{\circ} \mathrm{C}$ for $30 \mathrm{sec}$ and $60^{\circ} \mathrm{C}$ for $1 \mathrm{~min}$ and $72^{\circ} \mathrm{C}$ for $1 \mathrm{~min}$; final extension was performed at $72^{\circ} \mathrm{C}$ for $5 \mathrm{~min}$. The PCR products following electrophoresis were purified from $1.5 \%$ agarose gel by TIANgel Midi Purification kit (Tiangen Biotech $^{\circledR}$, Beijing, China) per supplier's specification. For the veracity of DNA sequencing, PCR products were cloned into pMD ${ }^{\circledR} 19-\mathrm{T}$ Simple Vector (Takara) and transformed into competent cells of Escherichia coli DH5a. Using LB-AgarPower medium with ampicillin $(100 \mu \mathrm{g} / \mathrm{ml})$, five monoclones per sample were picked for sequencing by 3730x1 DNA Analyzer (Applied Biosystems). Quality control for DNA methylation data was performed using BiQ (software tool for DNA methylation analysis; http://biq-analyzer.bioinf.mpi-inf.mpg.de/).

Statistical analysis. The Ct value (threshold cycle) was defined as the fractional cycle number at which the fluorescence passed the fixed threshold. $\Delta \mathrm{Ct}$ represented the expression 

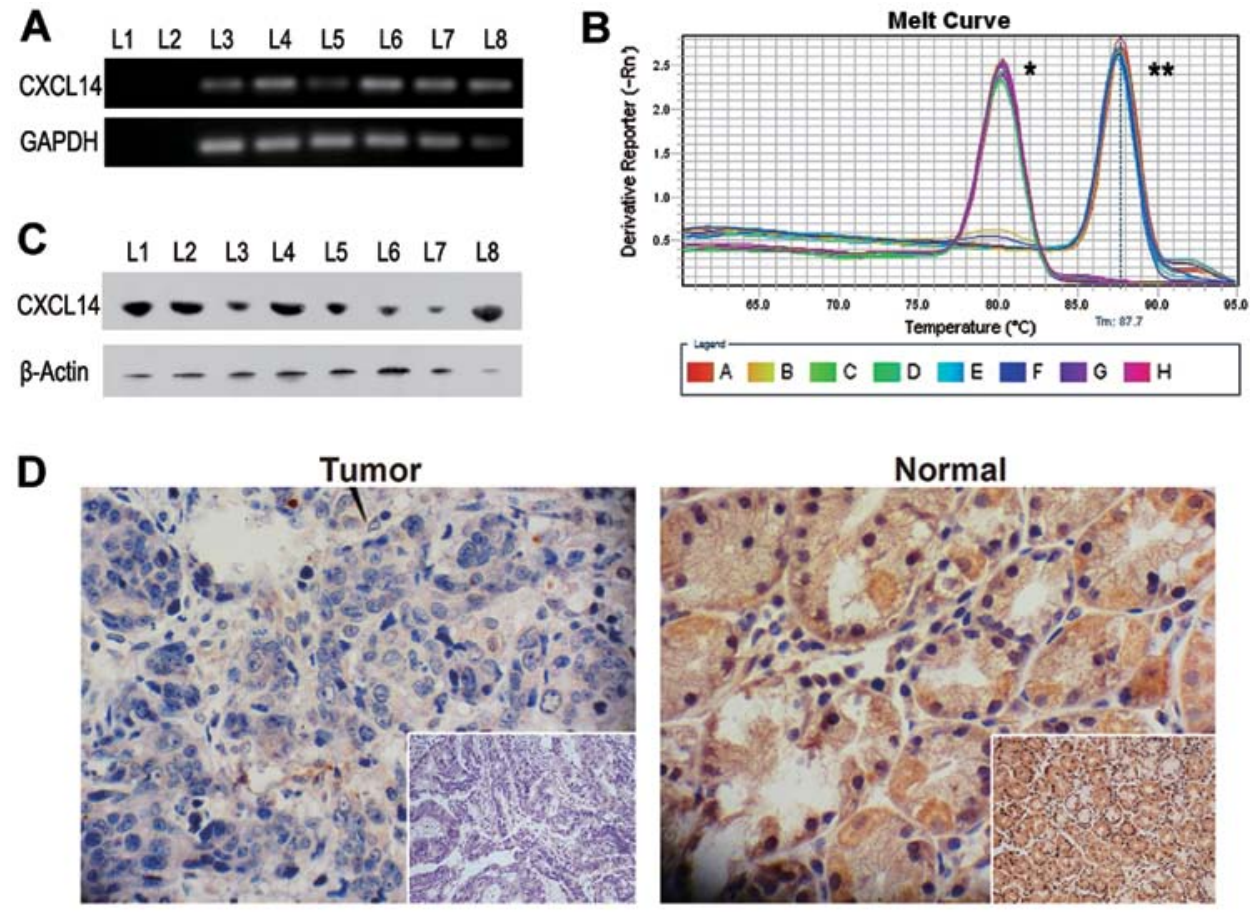

E

$\mathbf{F}$
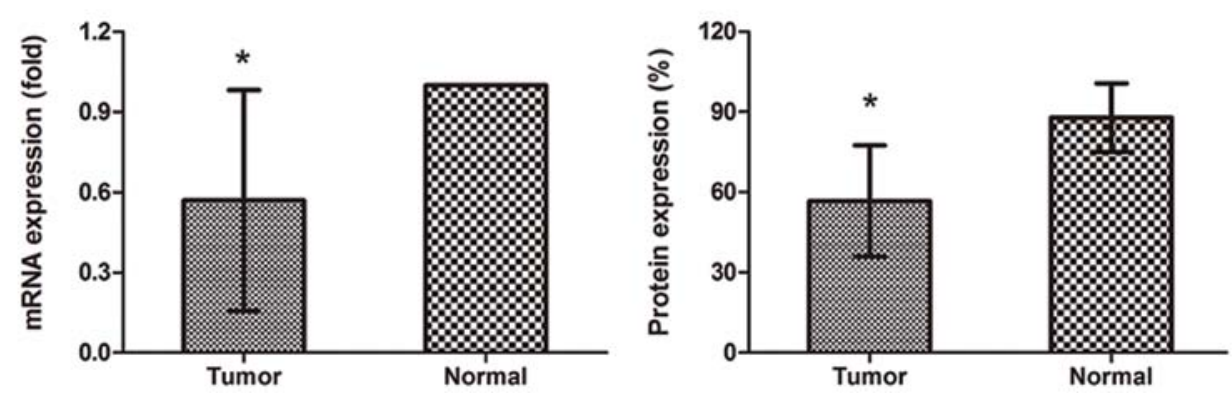

Figure 1. Expression of CXCL14 in human gastric cancer and gastric tissues on mRNA or protein levels. (A) CXCL14 mRNA expression by improved protocol; L1, blank control; L2, RNA control; L3-8, tumor 1, normal 1, tumor 2, normal 2, tumor 3, normal 3. (B) Melting curve; "hGAPDH; ${ }^{* *}$ CXCL14. (C) CXCL14 protein levels by western blotting; L1-8, tumor 1, normal 1, tumor 2, normal 2, tumor 3, normal 3, tumor 4, normal 4. (D) Expression and localization of CXCL14 protein in gastric tissues by immunohistochemistry; magnification x 200 and x400, respectively. (E) CXCL14 mRNA levels in normal gastric tissues $(\mathrm{n}=60)$ and gastric cancer $(\mathrm{n}=60)$; ${ }^{*} \mathrm{P}<0.001$. (F) Semi-quantitative analysis of CXCL14 immunoreactivity; $\mathrm{n}=60 ;{ }^{*} \mathrm{P}<0.001$.

difference between target RNA and internal control gene. $\Delta \Delta \mathrm{Ct}$ represented the difference in value between $\Delta \mathrm{Ct}$ of tumor tissues or the cells in experimental group and $\Delta \mathrm{Ct}$ of normal tissues or control group. The normalized mRNA expression level in a cancer specimen is $2^{-\Delta \Delta C t}$. For the paired normal tissue sample or control group, $\Delta \Delta \mathrm{Ct}$ equal to 0 and $2^{-\Delta \Delta \mathrm{Ct}}$ equal to 1 . Because most mRNA level fit the gaussian distribution, one-sample t-test, independent sample t-test and Kruskal-Wallis $\mathrm{H}$ test are used to evaluate the differences of the miRNA expression between different groups. The difference of DNA methylation in paired specimens were analysed by $\chi^{2}$ test. In Kaplan-Meier survival curve, we define high expression as the fold change $>1$ and low expression as $<1$, probability of survival was compared by log-rank test. The quantified RNA data and other clinicopathological features were selected by stepwise regression selection as covariates to access the effects to survival time in Cox proportional hazard regression model. Level of significance was defined as $\mathrm{P}<0.05$. All analysis were carried out by SPSS version 16.0 for Windows.

\section{Results}

Downregulation of CXCL14 expression in human gastric adenocarcinoma. To explore the expression of CXCL14 in gastric cancer, we firstly design a sensitive and specific realtime PCR to access the mRNA level. Electrophoresis indicated that a single band of CXCL14 or hGAPDH at the appropriate position (156 bp for CXCL14 and $101 \mathrm{bp}$ for hGAPDH) and no PCR product was obtained from the 'minus-RT' control in which reverse transcriptase was omitted from the reactions (Fig. 1A). The melting-curves of CXCL14 and hGAPDH were sharply defined curves with a narrow peak, indicating that pure, homogeneous PCR products were produced (Fig. 1B). The combination of melting curves and gel electrophoresis confirmed the PCR specificity.

Using the real-time PCR method described above, we further endeavored to determine the expression patterns in paired samples consisting of tumor and normal gastric tissues $(\mathrm{n}=60$ respectively). As shown in Fig. 1E, the expression level of CXCL14 in tumor samples was lower than that in the controls 
A

-454

.239 II [

Primer

E AP-1 binding sequence

$\triangle$ Transcription initiation site

CpG island

Q8 GC box $\quad$ m

A Translation initiation site

B

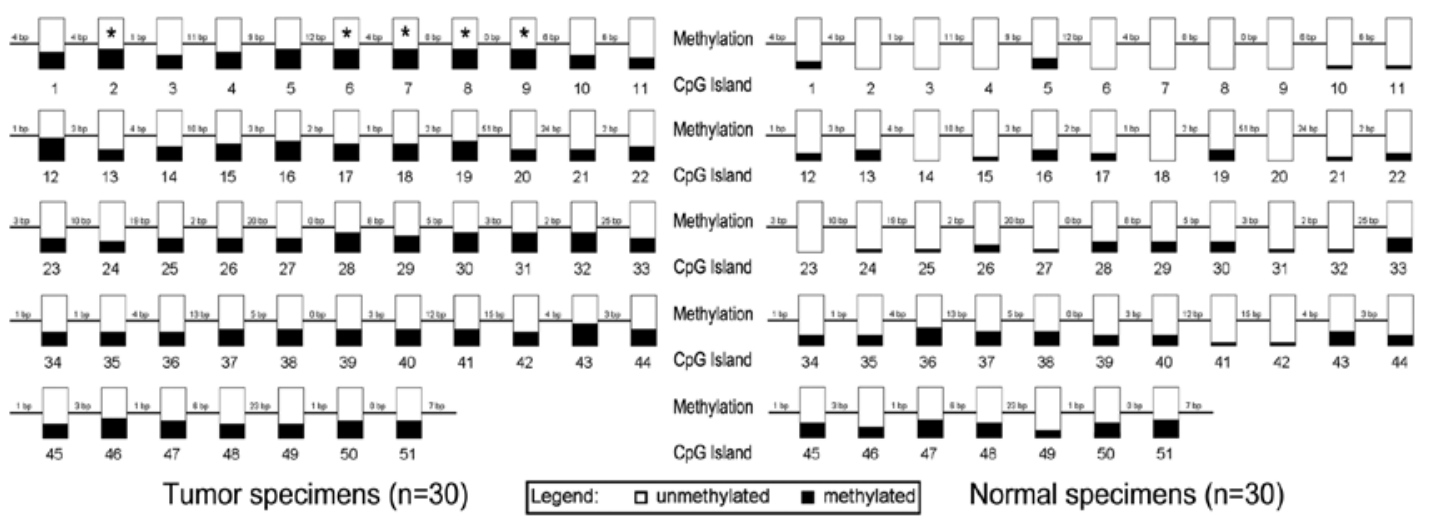

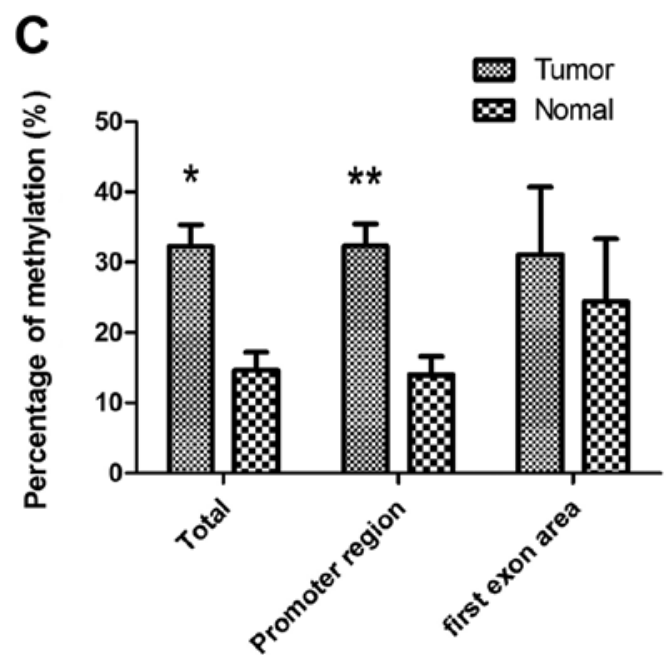

CpG islands

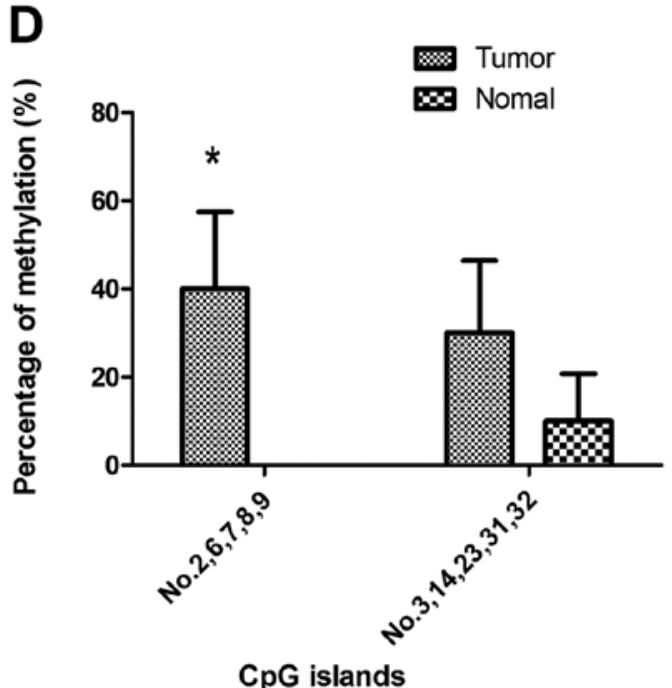

Figure 2. Bisulfite sequencing PCR in human gastric cancer and gastric tissues. (A) Analysis of BSP amplified fragments. (B) Methylation level of 51 CpG islands in paired specimens ( $\mathrm{n}=60,5$ clones per sample); ${ }^{*} \mathrm{CpG}$ island has statistical difference in paired samples. (C) Analysis of DNA methylation by groups; ${ }^{*} \mathrm{P}<0.001 ;{ }^{* *} \mathrm{P}<0.001$. (D) Analysis of DNA methylation by seperated $\mathrm{CpG}$ island; ${ }^{*} \mathrm{P}<0.001$.

$(\mathrm{P}<0.001)$. The mean of relative expression of CXCL14 $\left(2^{-\Delta \Delta C t}\right)$ was 0.569 in tumor samples, with that in non-tumor control samples set at 1.000 .

The specificity of the antibody against CXCL-14 was examined by western blotting (Fig. 1C). However, the difference of chemiluminescence reaction between paired specimens was probably eliminated by the normal gastric epithelial cells in tumor tissues. Immunohistochemical analysis also indicated that CXCL14 protein levels in gastric adenocarcinoma tissues presented a loss of CXCL14 expression when compared with paired normal gastric tissues (Fig. 1D). Normal tissues $(n=30)$ were strongly positive stained by CXCL14 antibody, whereas tumor tissues ( $\mathrm{n}=30)$ were low or absent of CXCL14 expression. Semi-quantitative analysis (Table II) indicated that approxi- mately half the cancer samples had downregulated protein expression $>25 \%$, the remaining cancer samples declined more severely by $\geq 50 \%$ (mean, $60 \%$ ). On the contrary, most normal tissues were filled with brown staining (mean, 90\%, $\mathrm{P}<0.001$ ) under the microscope (Fig. 1F).

Abnormal hypermethylation of CXCL14 promoter region in tumor tissues. Following NCBI and Komori et al (20) conclusion, there was an atypical TATA-like TATTAA sequence, an AP-1 binding sequence, $4 \mathrm{GC}$ boxes and $51 \mathrm{CpG}$ islands included in this CXCL14 bisulfite-sequencing PCR product. It has been reported that transcription initiation site (downstream $60 \mathrm{bp}$ of TATTAA sequence), translation initiation site (ATG) and the first exon area also exist (20) (Fig. 2A). They are likely 
Table II. Semi-quantitative analysis of CXCL14 immunoreactivity in cancer and normal tissues.

\section{Immunoreactivity}

$\mathrm{n}$

Tumor slides

$$
\begin{aligned}
& ++++ \\
& +++ \\
& ++ \\
& + \\
& -
\end{aligned}
$$

Normal slides

$$
\begin{aligned}
& ++++ \\
& +++ \\
& ++ \\
& +
\end{aligned}
$$$$
-
$$

mens were methylated, in contrast of $32.29 \%(494 / 1530)$ in tumor (Fig. 2B and C). The methylation status of combined $\mathrm{CpG}$ islands showed statistical significance $(\mathrm{P}<0.001)$. Further investigation indicated that CXCL14 promoter region revealed statistical difference between samples obtained from normal $(13.96 \%, 201 / 1440)$ and tumor tissues $(32.36 \%$, 466/1440, $\mathrm{P}<0.001)$, whereas no methylation difference was found between normal and cancer samples in first exon area $(\mathrm{P}=0.498)$ (Fig. 2C). Furthermore, we found that each $\mathrm{CpG}$ island had different effect on methylation status in cancer. Hypermethylation of nos. 2, 6, 7, 8 and $9 \mathrm{CpG}$ island, as group 1 , had statistical difference between normal and tumor tissues $(\mathrm{P}<0.001)$ and nos. 3, 14, 23, 31 and $32 \mathrm{CpG}$ island, as group 2 , showed a potential difference existed $(\mathrm{P}=0.053)$ (Fig. 2D). Each CpG island inner-group showed the same methylation state in hypermethylated $\mathrm{CpG}$ islands.

Demethylation restored the expression of CXCL14 in gastric cancer cell lines. To further verify the above phenomenon, AGS, BGC823, MGC803 and SGC7901 gastric cancer cell lines were treated with 5-Aza-2'-deoxycytidine to recover the demethylation state of CXCL14 gene CpG islands. Fig. 3A illustrates that with 5-Aza-2'-deoxycytidine treatment, AGS cells were restored to upregulate CXCL14 mRNA level $(\mathrm{P}=0.019)$ compared with control group $(0 \mu \mathrm{mol} / \mathrm{l})$. The BSP verified the demethylating efficacy and reversible methylation affected CXCL14 expression. As shown in Fig. 3B, the rate of methylated $\mathrm{CpG}$ islands in the CXCL14 promoter region was reduced from $85.62 \%(655 / 765)$ to $12.55 \%(96 / 765)(\mathrm{P}<0.001)$ but no statistical difference was revealed with concentration gradients $(5,10,15$ and $25 \mu \mathrm{mol} / 1, \mathrm{P}=0.825)$. The same results were explored in BGC823 and SGC7901, it seems that the

to be the composition of methylation patterns. Considering the downregulation of CXCL14 in gastric cancer and the many cis-function elements contained in CXCL14 genome, we further analyzed the methylation state of CXCL14 in promoter and first exon area.

Bisulfite sequencing of tumor and normal tissues revealed that $14.58 \%(223 / 1530)$ of the $51 \mathrm{CpG}$ sites in normal speci-
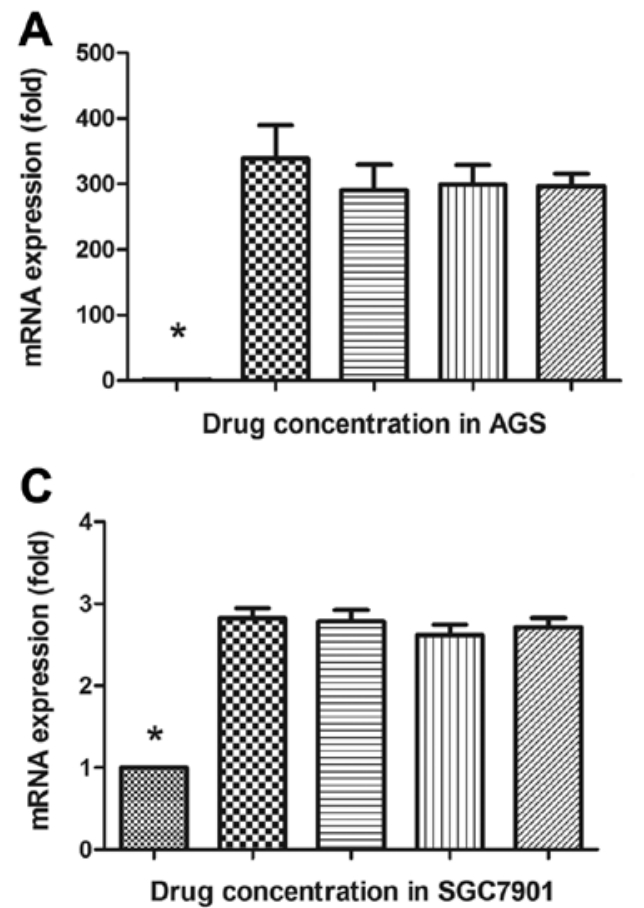
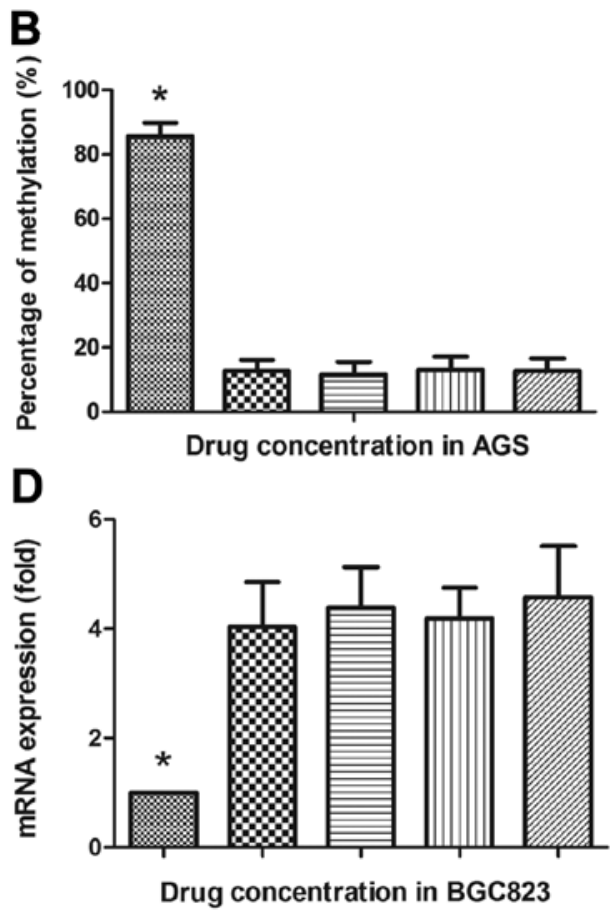

Figure 3. Demethylation effect on gastric cancer cell lines. (A) 5-Aza-2'-deoxycytidine restored CXCL14 mRNA expression without concentration-dependent in AGS; *P=0.019. (B) 5-Aza-2'-deoxycytidine downregulated methylation level of AGS; *P<0.001. (C) 5-Aza-2'-deoxycytidine restored CXCL14 mRNA expression without concentration-dependent in SGC7901; $\mathrm{P}<0.001$. (D) 5-Aza-2'-deoxycytidine restored CXCL14 mRNA expression without concentrationdependent in BGC823; ${ }^{*} \mathrm{P}<0.001$. 

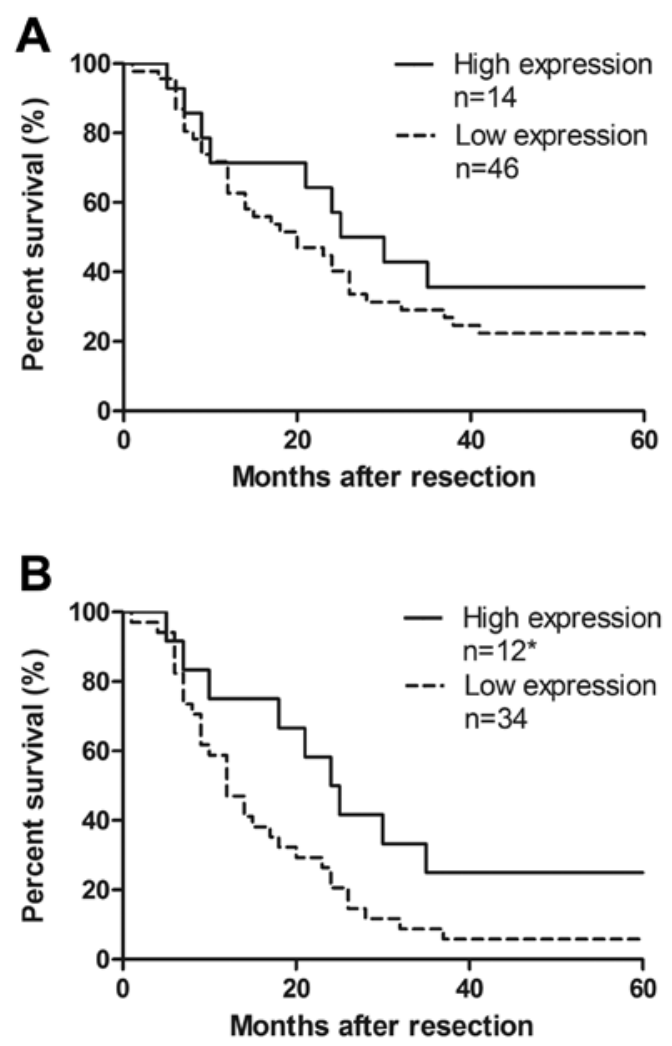

Figure 4. Analysis of the 5-year survival rate; (A) CXCL14 in overall survival rate. (B) Survival analysis of CXCL14 in stage III/IV; ${ }^{*} \mathrm{P}=0.046$.

restoration of CXCL14 expression was associated with the presence of hypomethylating agents, not dose-dependently ( $\mathrm{P}<0.001$, both) (Fig. 3C and D). However, no statistical difference was shown between study cohort and control cohort in $\operatorname{MGC} 803(\mathrm{P}=0.353)$.

Correlation between CXCL14 mRNA expression and clinical analysis. The depth of penetration was associated with CXCL14 mRNA relative level (especially for $\mathrm{T} 4, \mathrm{P}<0.001$ ). However, there was no correlation between CXCL14 relative expression and general clinicopathological features of gastric cancer, such as age, gender, tumor location, differentiation, lymph node metastasis, TNM classification, and tumor markers (Table I). We defined high CXCL14 relative expression as the fold change $>1$ and low expression as $<1$. The overall survival rate illustrated that the cohort with higher expression of CXCL14 showed no improved survival compared to that with lower level ( $\mathrm{P}=0.270$, Fig. 4A). Respective median survival time of stage III/IV in the two groups showed significant difference, to 12 or 24 months, respectively $(\mathrm{P}=0.046$, Fig. $4 \mathrm{~B})$. Analysis of Cox proportional hazard model showed most clinicopathological features are excluded, but combined TNM classification, lymphatic invasion and CXCL14 mRNA expression has an effect on survival time $(\mathrm{P}<0.001)$. The risk ratio of $\mathrm{CXCL}-14$ reached $0.394(95 \% \mathrm{CI}, 0.195,0.793 ; \mathrm{P}=0.009)$ as $\mathrm{TNM}$ was 2.952 (95\% CI, 1.549, 4.335; $\mathrm{P}<0.001)$ and lymphatic invasion was 2.133 (95\% CI, 1.344, 3.386; P=0.001). Therefore, CXCL14 might be an independent positive factor in prognosis, as the death risk of low expression group was 2.538-fold higher than the high one.

\section{Discussion}

The development of neoplasm is dependent on the balance of tumor progression and inhibition genes. As a multifunctional chemokine, CXCL14 might use distinct signal transduction pathways to take part in the inhibition and development of neoplasm. In tissues of prostate and pancreas cancers, CXCL14 showed higher expression compared to normal control $(18,19)$. However, in our present study, we reported for the first time the downregulation of CXCL14 expression in gastric cancer. Survival analysis showed CXCL14 levels were positively correlated with survival time in stage III/IV and invasive depth although CXCL14 expressions showed no correlation with clinicopathological features of gender, age, tumor location, size, differentiation, lymph node metastasis, anatomic stage or common tumor markers. Consistent with our results, several studies also showed the decreased or absent expression of CXCL14 in breast cancers, renal carcinomas, lung cancers, head and neck squamous cell carcinomas and cervical cancer $(6,8,16,17,21)$.

It is well reported that CXCL14 can chemoattract several classes of immune cells including monocyte-divided macrophagocyte, immature dendritic cells (iDCs), natural killer (NK) cells and B cells $(8,11,22)$. Due to lack of CXCL14 expression in solid tumors, few immune cells were assembled in cancer tissues resulting in local immune response deficiencies, including attenuated immune surveillance, immune evasion, weakened antigen presentation and disordered immune internal environment (11). Besides immunological anticancer mechanism, CXCL14 could also suppress tumorous vasculature by inhibiting the chemotaxis of vascular smooth muscle cells and the formation of microvascular system $(3,7,23)$. CXCL14 also directly affects the proliferation, invasion and migration of tumor cells $(13,16,23)$. Mechanisms involved in CXCL14 function in the development of gastric cancer still needs to be further explored.

Literature over the years have investigated several CXCL14 related up-stream genes to state the different expression between normal and tumor tissues. It has been reported that the Ras/Raf/MEK/ERK/MAPK signal pathway, RhoA, ROCK signal pathway, calcium/calmodulin signal pathway, reactive oxygen species imbalance and transcription factor SP-1 could influence the CXCL14 expression (24-27). DNA abnormal hypermethylation in $\mathrm{CpG}$ islands of promoters, related to gene silencing, is now recognized as a common feature for malignant tumors (28). In our study, methylation in CXCL14 promoter was analyzed by BSP method. Data indicated that methylation in CXCL14 promoter exists in gastric cancer and normal tissues, but the level of methylation of the latter is far below the former. No statistical difference existed in the first exon area. When checking $48 \mathrm{CpG}$ islands in promoter, nos. 2, 6, 7, 8 and $9 \mathrm{CpG}$ showed significant hypermethylation in tumor tissues $(\mathrm{P}<0.001)$. In addition, nos. 3, 14, 23, 31 and 32 have a potential difference $(\mathrm{P}=0.053)$. These islands might act as a potential diagnostic marker for gastric cancer. Which islands are involved in CXCL14 silencing in gastric cancer requires further investigation. 
In conclusion, as a new member of CXC subfamily of chemokines, CXCL14 has a role in the development and progression of gastric cancer. Hypermethylation in promoter region causes the low expression of CXCL14 in gastric adenocarcinoma tissues. The level of CXCL14 expression provides a valuable adjuvant parameter in predicting the prognosis of gastric cancer patients and thus a potential therapeutic target.

\section{Acknowledgements}

This study was supported by National Natural Science Foundation of China (81001343), the Zhejiang Provincial Natural Science Foundation of China (Y2100660 and Y2100909) and the Wenzhou Science and Technology Bureau (H20100028).

\section{References}

1. Kamangar F, Dores GM and Anderson WF: Patterns of cancer incidence, mortality, and prevalence across five continents: defining priorities to reduce cancer disparities in different geographic regions of the world. J Clin Oncol 24: 2137-2150, 2006.

2. Crew KD and Neugut AI: Epidemiology of gastric cancer. World J Gastroenterol 12: 354-362, 2006.

3. Shellenberger TD, Wang M, Gujrati M, et al: BRAK/CXCL14 is a potent inhibitor of angiogenesis and a chemotactic factor for immature dendritic cells. Cancer Res 64: 8262-8270, 2004.

4. Balkwill F: The significance of cancer cell expression of the chemokine receptor CXCR4. Semin Cancer Biol 14: 171-179, 2004.

5. Zlotnik A, Burkhardt AM and Homey B: Homeostatic chemokine receptors and organ-specific metastasis. Nat Rev Immunol 11: 597-606, 2011.

6. Hromas R, Broxmeyer HE, Kim C, et al: Cloning of BRAK, a novel divergent CXC chemokine preferentially expressed in normal versus malignant cells. Biochem Biophys Res Commun 255: 703-706, 1999.

7. Hara T and Nakayama Y: CXCL14 and insulin action. Vitam Horm 80: 107-123, 2009.

8. Sleeman MA, Fraser JK, Murison JG, et al: B cell- and monocyte-activating chemokine (BMAC), a novel non-ELR alpha-chemokine. Int Immunol 12: 677-689, 2000.

9. Frederick MJ, Henderson Y, Xu X, et al: In vivo expression of the novel CXC chemokine BRAK in normal and cancerous human tissue. Am J Pathol 156: 1937-1950, 2000.

10. Meuter S and Moser B: Constitutive expression of CXCL14 in healthy human and murine epithelial tissues. Cytokine 44: 248-255, 2008.

11. Kurth I, Willimann K, Schaerli P, Hunziker T, Clark-Lewis I and Moser B: Monocyte selectivity and tissue localization suggests a role for breast and kidney-expressed chemokine (BRAK) in macrophage development. J Exp Med 194: 855-861, 2001.
12. Maerki C, Meuter S, Liebi M, et al: Potent and broad-spectrum antimicrobial activity of CXCL14 suggests an immediate role in skin infections. J Immunol 182: 507-514, 2009.

13. Shurin GV, Ferris RL, Tourkova IL, et al: Loss of new chemokine CXCL14 in tumor tissue is associated with low infiltration by dendritic cells (DC), while restoration of human CXCL14 expression in tumor cells causes attraction of DC both in vitro and in vivo. J Immunol 174: 5490-5498, 2005.

14. Starnes T, Rasila KK, Robertson MJ, et al: The chemokine CXCL14 (BRAK) stimulates activated NK cell migration: implications for the downregulation of CXCL14 in malignancy. Exp Hematol 34: 1101-1105, 2006.

15. Juremalm $M$ and Nilsson G: Chemokine receptor expression by mast cells. Chem Immunol Allergy 87: 130-144, 2005.

16. Tessema M, Klinge DM, Yingling CM, Do K, Van Neste L and Belinsky SA: Re-expression of CXCL14, a common target for epigenetic silencing in lung cancer, induces tumor necrosis. Oncogene 29: 5159-5170, 2010.

17. Balkwill FR: The chemokine system and cancer. J Pathol 226: 148-157, 2012.

18. Augsten M, Hagglof C, Olsson E, et al: CXCL14 is an autocrine growth factor for fibroblasts and acts as a multi-modal stimulator of prostate tumor growth. Proc Natl Acad Sci USA 106: 3414-3419, 2009

19. Wente MN, Mayer C, Gaida MM, et al: CXCL14 expression and potential function in pancreatic cancer. Cancer Lett 259: 209-217, 2008.

20. Komori R, Ozawa S, Kato Y, Shinji H, Kimoto S and Hata R: Functional characterization of proximal promoter of gene for human BRAK/CXCL14, a tumor-suppressing chemokine. Biomed Res 31: 123-131, 2010.

21. Park CR, You DJ, Kim DK, et al: CXCL14 enhances proliferation and migration of NCI-H460 human lung cancer cells overexpressing the glycoproteins containing heparan sulfate or sialic acid. J Cell Biochem 114: 1084-1096, 2013.

22. Mokhtar NM, Cheng CW, Cook E, Bielby H, Smith SK and Charnock-Jones DS: Progestin regulates chemokine (C-X-C motif) ligand 14 transcript level in human endometrium. Mol Hum Reprod 16: 170-177, 2010.

23. Izukuri K, Suzuki K, Yajima N, et al: Chemokine CXCL14/ BRAK transgenic mice suppress growth of carcinoma cell transplants. [corrected]. Transgenic Res 19: 1109-1117, 2010.

24. Miyamoto C, Maehata Y, Ozawa S, et al: Fasudil suppresses fibrosarcoma growth by stimulating secretion of the chemokine CXCL14/BRAK. J Pharmacol Sci 120: 241-249, 2012.

25. Ikoma T, Ozawa S, Suzuki K, et al: Calcium-calmodulin signaling induced by epithelial cell differentiation upregulates BRAK/CXCL14 expression via the binding of SP1 to the BRAK promoter region. Biochem Biophys Res Commun 420: 217-222, 2012.

26. Ozawa S, Kato Y, Ito S, et al: Restoration of BRAK/CXCL14 gene expression by gefitinib is associated with antitumor efficacy of the drug in head and neck squamous cell carcinoma. Cancer Sci 100: 2202-2209, 2009.

27. Pelicano H, Lu W, Zhou Y, et al: Mitochondrial dysfunction and reactive oxygen species imbalance promote breast cancer cell motility through a CXCL14-mediated mechanism. Cancer Res 69: 2375-2383, 2009.

28. Issa JP: CpG island methylator phenotype in cancer. Nat Rev Cancer 4: 988-993, 2004. 